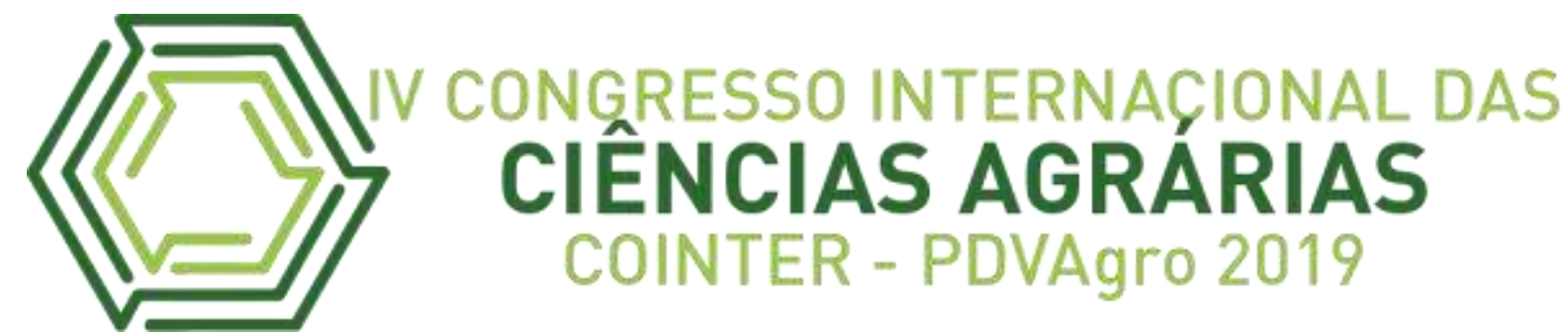

\title{
A PROMOÇÃO DA SAÚdE BUCAL POR MEIO DO USO DE UMA CARTILHA INFORMATIVA
}

\section{LA PROMOCION DE LA SALUD BUCAL MEDIANTE EL USO DE UN FOLLETO INFORMATIVO}

\section{THE PROMOTION OF THE BUCCAL HEALTH THROUGH THE USE OF AN INFORMATIVE BOOKLET}

\author{
Apresentação: Comunicação Oral \\ Levi Araujo Bezerra ${ }^{1}$; Luiz Carlos Alves de Souza ${ }^{2}$. \\ DOI: https://doi.org/10.31692/2526-7701.IVCOINTERPDVAgro.2019.0187
}

\begin{abstract}
Resumo
A promoção da saúde e sua prevenção, estão incluídas nas diretrizes da atenção básica e são ações que devem ser realizadas de maneira multiprofissional e interdisciplinar, nesse contexto, o ambiente escolar apresenta-se como um excelente lugar para o desenvolvimento e aplicação de recursos didáticos que tragam uma abordagem multidisciplinar, e que possam contribuir no aprendizado e desenvolvimento de novas práticas promotoras da saúde, diminuindo assim, índices de agravos à saúde bucal dos escolares, Assim, o uso de recursos didáticos como cartilhas, pode ser uma alternativa promissora no desenvolvimento da aprendizagem e promoção da mudança conceitual e significativa, cujos alunos possam compreender a importância da escovação adequada de seus dentes, na manutenção da saúde bucal. Este estudo tem por objetivo descrever o processo de construção de uma cartilha informativa para à promoção da saúde bucal e analisar as contribuições de sua utilização como recurso didático no ensino da escovação bucal, para alunos de escolas públicas municipais na zona rural em Vitória de Santo Antão - PE. O método utilizado neste estudo foi a pesquisa-ação, desenvolvida em seis etapas: escolha do conteúdo; produção e seleção das ilustrações; preparo do conteúdo, tomando como base a literatura científica; avaliação do material por parte de profissionais da área da educação e por fim o uso da cartilha como recurso didático. O trabalho final teve o título "Higiene bucal: como fazer a escovação adequada". Este recurso, foi bem aceito e avaliado por professores e estudantes da área da educação que receberam as cartilhas e puderam opinar com sugestões de modificações que possibilitaram a produção de um recurso didático enriquecedor e esclarecedor para o público alvo.
\end{abstract}

Palavras-Chave: saúde bucal, educação em saúde, cartilha educativa, educação no campo. Resumen

\footnotetext{
${ }^{1}$ Graduando em Ciências Biológicas, Universidade Federal de Pernambuco, levitj1.lab@gmail.com

${ }^{2}$ Mestre em educação agrícola, professor do Instituto Federal de Pernambuco Campus Vitória de Santo Antão, nagusto.eaf@hotmail.com
} 
La promoción y prevención de la salud se incluyen en las pautas de atención primaria y son acciones que deben realizarse de manera multidisciplinaria e interdisciplinaria. En este contexto, el entorno escolar es un lugar excelente para el desarrollo y la aplicación de recursos didácticos que aportan Un enfoque multidisciplinario que puede contribuir al aprendizaje y el desarrollo de nuevas prácticas de promoción de la salud, reduciendo así la tasa de daño a la salud bucal de los escolares, por lo que el uso de los recursos de enseñanza como folletos puede ser una alternativa prometedora en el desarrollo del aprendizaje y promover un cambio conceptual y significativo, cuyos estudiantes puedan comprender la importancia de cepillarse los dientes adecuadamente para mantener la salud bucal. Este estudio tiene como objetivo describir el proceso de construcción de un folleto informativo para la promoción de la salud bucal y analizar las contribuciones de su uso como recurso didáctico en la enseñanza del cepillado bucal, para estudiantes de escuelas públicas municipales en el área rural de Vitória de Santo Antão. - PE. El método utilizado en este estudio fue la investigación de acción, desarrollada en seis pasos: elección de contenido; producción y selección de ilustraciones; preparación del contenido, basado en la literatura científica; evaluación del material por profesionales en el campo de la educación y, finalmente, el uso del folleto como recurso didáctico. El trabajo final se tituló "Higiene oral: cómo hacer el cepillado adecuado". Este recurso fue bien aceptado y evaluado por maestros y estudiantes en el área de educación que recibieron los folletos y pudieron dar su opinión con sugerencias de modificaciones que permitieron la producción de un recurso didáctico enriquecedor y esclarecedor para el público objetivo.

Palabras Clave: Salud Bucal, Educación para la salud, Manual educativo, Educación rural.

\begin{abstract}
Health promotion and prevention are included in the primary care guidelines and are actions that should be performed in a multidisciplinary and interdisciplinary manner. In this context, the school environment is an excellent place for the development and application of teaching resources that bring a multidisciplinary approach that can contribute to the learning and development of new health-promoting practices, thus reducing the rate of harm to the oral health of schoolchildren. Thus, the use of teaching resources as booklets may be a promising alternative in the development of learning. and promoting conceptual and significant change, whose students can understand the importance of proper brushing of their teeth in maintaining oral health. This study aims to describe the process of constructing an information booklet for the promotion of oral health and to analyze the contributions of its use as a didactic resource in the teaching of oral brushing, for students of municipal public schools in the rural area of Vitória de Santo Antão. - PE. The method used in this study was action research, developed in six steps: choice of content; production and selection of illustrations; preparation of the content, based on the scientific literature; evaluation of the material by professionals in the field of education and finally the use of the booklet as a didactic resource. The final work was entitled "Oral Hygiene: How to do the proper brushing". This resource was well accepted and evaluated by teachers and students in the area of education who received the booklets and were able to give their opinion with suggestions for modifications that enabled the production of an enriching and enlightening didactic resource for the target audience.
\end{abstract}

Keywords: Oral health, Health Education, Educational Primer, Rural Education. 


\section{Introdução}

No Brasil, a saúde bucal foi caracterizada como uma assistência pública deficiente e de limitações do acesso da população, causando superlotação das unidades de saúde da família (PEREIRA, 2018). Diante dos problemas enfrentados pela saúde, tornou-se indispensável à elaboração de uma política de saúde bucal, a qual foi desenvolvida e promovida pelo Governo Federal.

Em 2003 foi instaurado o Programa Brasil Sorridente, abordando diretrizes e normas que visaram à ampliação e à qualificação do atendimento em saúde bucal na atenção básica, proporcionando o desenvolvimento de atividades que promoveram a saúde e a prevenção de doenças, possibilitando para os usuários do sistema público de Saúde, a acessibilidade aos serviços (BULGARELI et al., 2014).

O cuidado com a saúde bucal deve ser estimulado desde os primeiros anos de vida, pois nesta fase a criança responde muito bem ao desenvolvimento de hábitos e execução de novas atividades. Fornecer informações sobre cuidados bucais associados a ações preventivas como a escovação supervisionada, são eficazes na redução de cárie, sangramento gengival entre outros problemas bucais (BARRETO et al., 2013).

A sala de aula exerce grande influência sobre a saúde dos educandos, e por este motivo vários conceitos surgiram, atrelando a saúde e a educação, tendo por objetivo estimular o estilo de vida saudável, a partir do desenvolvimento de ambientes educativos que apoiem e conduzam à promoção da saúde, que vêm sendo abordada por diversos pesquisadores, eles apontam a relevância de programas educativos sobre os cuidados necessários com a higiene bucal (AQUILANTE et al., 2003; PEREIRA, 2018).

Segundo Garbin, (2011) a escola é o local mais indicado para construção dos hábitos de higiene bucal. No entanto, tornar as práticas educativas e preventivas em saúde um cotidiano didático pedagógico tem sido um desafio para as instituições de ensino, por necessitarem da cooperação entre saúde e educação (CARVALHO et al., 2013).

A escola é um lugar privilegiado para a realização de intervenções promotoras de mudança de comportamentos e o desenvolvimento da autonomia na criança. O profissional de saúde, tem como atribuição alavancar ações na perspectiva do desenvolvimento da criança no ambiente escolar, por meio de projetos que articulem educação e saúde, para essa parceria entre saúde e educação, devem estar inseridas no projeto político-pedagógico das instituições educacionais (BRASIL, 2015). 
O sistema de saúde brasileiro tem mudado e passou a dar um maior apoio aos procedimentos de prevenção, investindo em programas que buscam a melhoria da atenção à saúde, para a prevenção e controle de doenças bucais (TEGAN, 2007).

A execução desses programas dispõe de diversos métodos para serem realizados, dentre eles escovação supervisionada, aplicação de flúor, palestras, cartazes, panfletos, entre vários outros meios informativos, que facilitem e possibilitem a aprendizagem significativa. Sendo necessário que a criança entenda de forma simples e didática a importância do cuidado com a saúde bucal. (ANTONIO et al., 2015).

Assim, o uso de recursos didáticos como cartilhas, pode ser uma alternativa promissora no desenvolvimento da aprendizagem e promoção da mudança conceitual e significativa, cujos alunos possam compreender a importância da escovação adequada de seus dentes, na manutenção da saúde bucal. Este estudo tem por objetivo, descrever o processo de confecção e utilização de uma cartilha informativa, como recurso didático no ensino da escovação bucal adequada para alunos de uma escola pública municipal em Vitória de Santo Antão - PE.

\section{Fundamentação Teórica}

Segundo Pereira, (2018) a saúde bucal foi caracterizada no Brasil, como uma assistência pública deficiente e com limitação de acesso da população, causando superlotação das Unidades de Saúde da família. Diante dos problemas enfrentados pela saúde, tornou-se indispensável à elaboração de uma política de saúde bucal, a qual foi desenvolvida e promovida pelo Governo Federal.

Bulgareli et al., (2014) relata que o Programa Brasil Sorridente, foi instaurado em 2003 abordando diretrizes e normas que objetivam a ampliação e à qualificação do atendimento em saúde bucal na atenção básica, proporcionando o desenvolvimento de atividades que promoveram a saúde e a prevenção de doenças, possibilitando acessibilidade para os usuários do Sistema Público de Saúde.

Esse cuidado com a saúde bucal deve ser estimulado desde os primeiros anos de vida, pois é nesta fase que a criança responde muito bem ao desenvolvimento de hábitos e execução de novas atividades. O Fornecimento de informações sobre saúde bucal associadas às ações preventivas, como a escovação supervisionada, são eficazes na prevenção de cárie, sangramento gengival entre outros problemas (BARRETO et al., 2013). 
A sala de aula exerce grande influência sobre a saúde dos alunos, e por este motivo vários conceitos surgiram, associados a saúde e a educação, tendo por objetivo estimular o estilo de vida saudável, a partir do desenvolvimento de ambientes educativos que apoiem à promoção da saúde, que vêm sendo abordada por diversos pesquisadores, que apontam a relevância de programas educativos sobre os cuidados necessários com a higiene bucal (AQUILANTE et al., 2003; PAES, (2016); PEREIRA, 2018).

Segundo Granville-garcia et al., (2012). Uma das contribuições para a promoção da saúde, é a educação pois permite a ampliação do entendimento sobre a saúde bucal, permitindo assim para o aluno, ter autonomia para cuidar de sua saúde desde os primeiros anos de vida.

Segundo Carvalho et al., (2013), a falta da pratica na higiene bucal e de orientações sobre o uso dos materiais adequados para a realização da higiene bucal são considerados problemas graves, pois podem conduzir a sérios transtornos bucais, e a implantação de métodos educativos em escolas, fazendo uso de peças teatrais e fantoches, tem contribuído na construção do conhecimento de vários alunos e modificado hábitos de higiene bucal.

Pereira et al., (2018), Tegan, Kozlowski e Rosario, (2007) apontam que, o ambiente escolar tem grande influência sobre a saúde dos jovens, provocando assim, o surgimento de conceitos como Escola promotora da saúde ou Escolas saudáveis, tendo por objetivo promover o estilo de vida saudável na escola, a partir do desenvolvimento de ambientes que apoiem e conduzam à promoção da saúde.

Antônio et al., (2015). Correlaciona a função do odontólogo e a do professor na promoção da saúde bucal, onde o cirurgião-dentista pode recomendar mudanças no comportamento relativo à saúde e o estimulo de hábitos favoráveis à sua prevenção. Enquanto que o educador, pode influir de maneira favorável junto à criança para a implantação de hábitos saudáveis. Sendo necessária a motivação para o alcance dos melhores índices de saúde e higiene bucal na população.

Turrioni et al., (2012), também aponta a importância de ambos os profissionais trabalharem em parceria para a promoção de uma melhor saúde bucal para os alunos, por meio da realização de um exame clínico realizado com 80 alunos que também responderam a um questionário, apresentaram grande melhora na avaliação, além de melhora na realização da técnica de escovação em 15 adolescente pertencente a sua amostra.

Pereira, et al. (2018) aponta o ambiente escolar como um excelente lugar para o desenvolvimento de novos hábitos e práticas saudáveis: 


\begin{abstract}
"Dessa forma, a escola surge como ambiente privilegiado para ações de promoção da saúde, devido à prática de atividades educativas principalmente relacionadas à construção do conhecimento crítico, estimulando a autonomia e o exercício dos seus direitos e deveres. $\mathrm{O}$ ambiente possibilita ainda a adoção de comportamentos e o desenvolvimento de habilidades relativas a atitudes mais saudáveis, além do controle das condições de saúde e qualidade de vida por todos os membros da comunidade escolar, como alunos, professores, funcionários, pais, dentre outros" (PEREIRA, et al.2018).
\end{abstract}

Silva e Freitas, (2011), Cárdenas et al. (2013), Queiroz et al. (2014), e Garbin et al. (2015) declaram que outros fatores devem ser levados em consideração, como alimentação saudável, tabagismo e obesidade, além de estabelecer que o sucesso do processo se deve ao reforço em casa por parte dos responsáveis. Os pais têm papel fundamental e devem estar orientados e conscientes da responsabilidade com a saúde bucal de seus filhos.

Como anteriormente citado, é necessário um trabalho multidisciplinar, voltado à educação para a saúde bucal, indispensável a um atendimento integral à criança. Monte, et al. (2015) aponta que educação sobre uma correta higiene bucal pode ser realizada nas escolas:

\begin{abstract}
"A educação sobre uma correta higiene bucal pode ser feita nas escolas, ruas e até mesmo dentro do próprio ambiente de trabalho. A promoção à saúde, utilizando as atividades educativas tem feito com que o índice de aprendizado e orientação da população aumentasse, diminuindo a falta de informação sobre os materiais adequados para o uso, como escova dental, fio dental, enxaguante bucal e creme dental. Além da visita ao profissional dentista periodicamente, fazendo sempre revisões, sem esquecer que nesta orientação é necessário informar principalmente as mães de recém-nascidos que eles também precisam de higienização bucal. Enfim, deve-se evitar que a população sem informação adequada e algumas vezes sem interesse, venha se prejudicar com a famosa carie bacteriana, precocemente, o que ocorre, muitas vezes, devido à carência de estímulos quando pequeninos, acarretando a perda precoce dos elementos dentários". (MONTE, et al. 2015)
\end{abstract}

A maneira como o ensino é realizado muitas vezes compromete o entendimento por parte do estudante, pois muitas vezes a fragmentação e dissociação com a realidade do estudante, dificultando o processo de ensino e aprendizagem, sendo assim, a maneira como o ensino vem sendo abordado, pouco desperta o interesse de buscar novos conhecimentos (ZANELLA, 2013).

Entre as várias ferramentas disponíveis para promover a educação e saúde, está o uso de cartilhas informativas. $\mathrm{O}$ uso de ilustrações é útil porque: reproduz, em vários aspectos a realidade; facilita a percepção de detalhes; reduz ou amplia o tamanho real dos objetos representados; torna próximos fatos e lugares; permite a visualização imediata de processos muito lentos ou rápidos.

As cartilhas são recursos amplamente utilizadas, pois são instrumentos facilitadores do processo ensino aprendizagem e auxiliam o professor nas aulas, aproximando o conteúdo do 
aluno. São bastante empregadas no ensino em geral, podendo ser usadas nas mais diversas áreas (MARTEIS et al., 2011).

Ainda de acordo com Marteis et al., (2011) as cartilhas comportam um grande número de informações, possibilitando que o assunto seja trabalhado de forma detalhada do que seria no formato de panfletos, apresentando texto de fácil leitura e ricamente ilustrada, as cartilhas tornam-se instrumentos valiosos que podem também ser usados para auxiliar o professor no ensino da higienização bucal.

\section{Metodologia}

Trata-se de um estudo do tipo pesquisa-ação que segundo Engel, (2000), A pesquisaação é um estudo participativo engajado, que desenvolve o conhecimento e a compreensão como parte da prática. É, portanto, uma maneira de se fazer pesquisa em situações práticas e que se deseja melhorar a compreensão desta.

A presente cartilha ${ }^{3}$, foi produzida por um discente do curso de Ciências Biológicas da UFPE-CAV, com coprodução de alunos do primeiro período do curso de odontologia da Faculdade Escritor Osman Da Costa Lins, durante os meses de abril e maio de 2019, para ser utilizada como recurso didático no ensino da escovação bucal adequada em uma escola pública municipal na zona rural em Vitoria de Santo Antão - PE.

A metodologia empregada na elaboração da cartilha foi baseada em algumas etapas: a escolha do tema; produção e seleção das ilustrações; preparo do conteúdo, tomando como base a literatura científica, elaboração da cartilha, avaliação do material, por profissionais da educação e por fim o uso da cartilha como recurso didático.

Figura 1 - Processos metodológicos adotados.

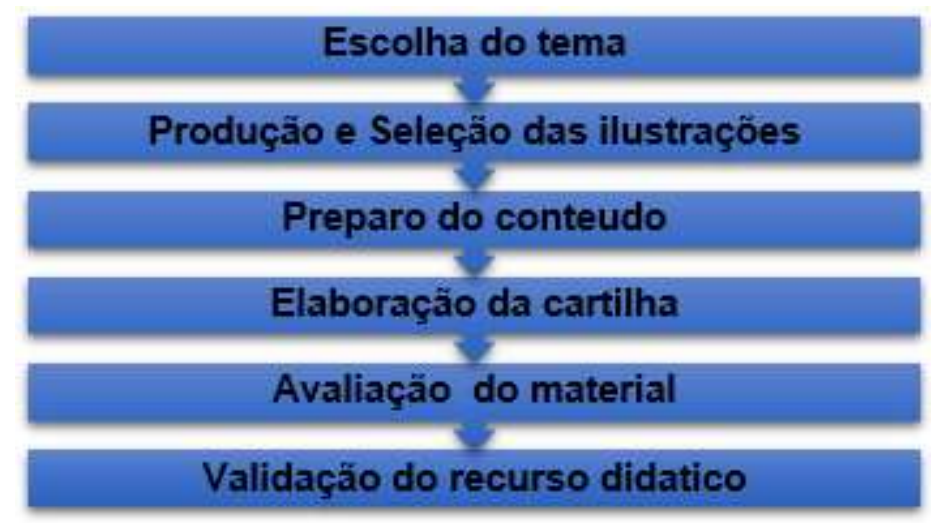

Fonte: Própria (2019).

\footnotetext{
${ }^{3}$ Link para acesso da cartilha(https://drive.google.com/file/d/1qxwCpWrm-TLVwsrUPWtkHnhTyl5kdwAg/view)
} 
A primeira etapa ocorreu por meio da procura de trabalhos científicos, relacionando os temas "saúde bucal" e "promoção da saúde no ambiente escolar", foi evidenciada baixa produção de estudos associando esses dois temas, as informações encontradas, foram utilizadas para direcionar o foco do tema, e na elaboração dos tópicos abordados na cartilha e suas principais ideias.

A fase de produção e seleção das ilustrações, ocorreu em paralelo a fase de preparo do conteúdo, pois dessa forma, as imagens e o texto são complementares, possibilitando assim, um melhor entendimento do conteúdo. O preparo do conteúdo foi embasado na literatura científica, para garantir a fidedignidade e confiabilidade das informações apresentadas. Alguns websites e livros foram acessados e utilizados como base para produção das ilustrações.

$\mathrm{Na}$ elaboração da cartilha, o conteúdo preliminar foi desenvolvido com o foco de apresentar apenas as informações consideradas essenciais. Esse conteúdo foi submetido ao trabalho de edição. O desenvolvimento dessa fase foi baseado em critérios previamente estabelecidos para todo o processo de produção da cartilha, isto é, a facilidade de leitura e clareza dos conteúdos apresentados.

Figura 2 - Imagem representativa de página da cartilha, nesta página, as imagens estão correlacionadas com o texto.

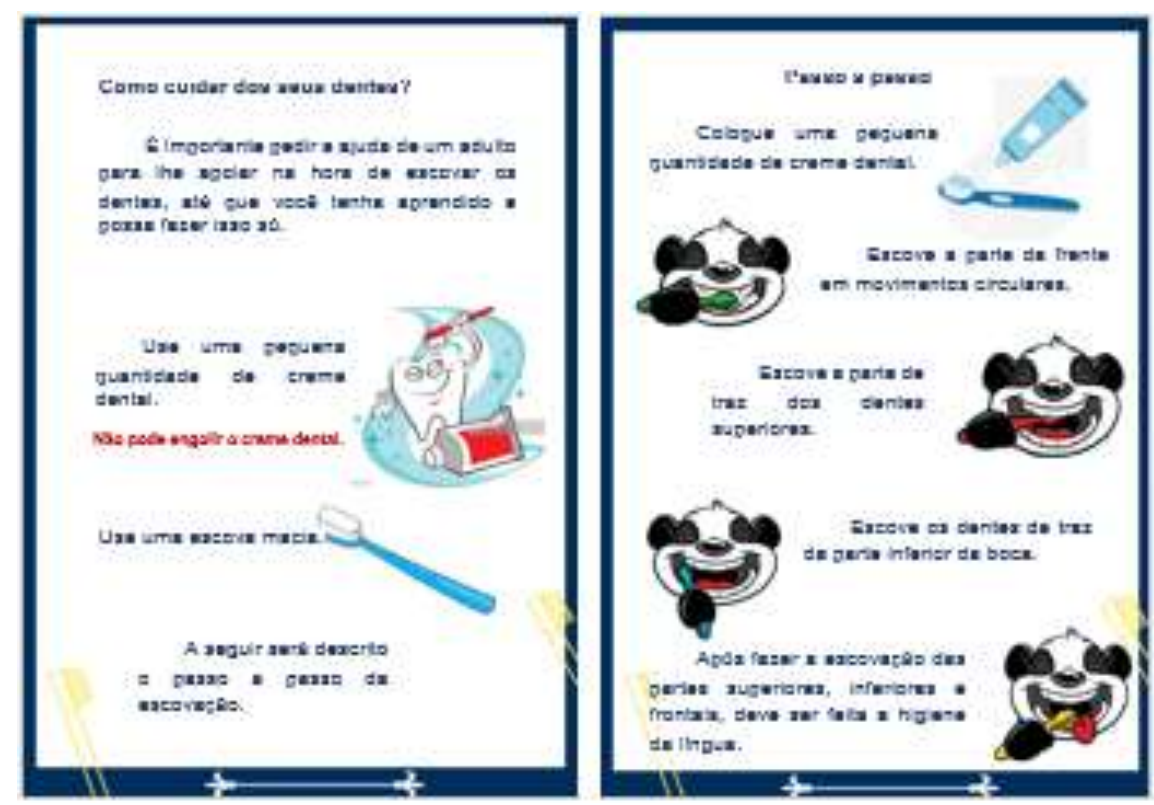

Fonte: Própria (2019)

A avaliação do primeiro material produzido, foi realizada por quinze estudantes do curso de Licenciatura em Ciências Biológicas da UFPE-CAV, que já haviam cursado as disciplinas de fundamentos da educação, didática e avaliação da aprendizagem, foi submetido também à 
avaliação de professores especialistas na área da educação, que fazem parte do quadro de servidores da UFPE-CAV, que aprovaram sua validação.

Cada tópico da cartilha foi avaliado e apontado se estavam em adequação, considerando a perspectiva de atender os leitores. Em relação à linguagem, foi avaliada a conveniência e a facilidade de compreensão e se os conceitos mais importantes estavam sendo abordados com um vocabulário claro e objetivo, voltado para atender o público alvo (crianças dos anos iniciais do ensino fundamental).

Também foram indicados possíveis erros conceituais. Em relação às figuras, avaliaram a adequação da composição visual, sua atratividade e organização, bem como a quantidade e a adequação das figuras. Ao concluir a validação, foi solicitado aos avaliadores fornecer uma opinião sobre a cartilha e suas recomendações foram aceitas e realizadas. A última versão da cartilha foi submetida a outro processo de revisão e edição, para possíveis ajustes que fossem necessários, até que por fim, ocorresse a utilização da cartilha como recurso didático.

Depois de passar pelo processo de avaliação e correção, a cartilha foi utilizada em uma escola pública de ensino fundamental, na zona rural de Vitoria de Santo Antão, cada escola escolheu uma de suas turmas para receber as cartilhas e a visita da equipe para apresentação do recurso e coleta de dados.

Antes da apresentação dos conteúdos, direção da escola assinou uma carta, concedendo anuência para o desenvolvimento das atividades, antes de assinar a carta de anuência, o gestor recebeu informações e ficou cientes dos objetivos e da metodologia da pesquisa acima citada, foi garantido o cumprimento das determinações éticas da resolução no 466/12 CNS/CONEP, a garantia de solicitar e receber esclarecimentos antes, durante e depois do desenvolvimento da pesquisa, de não haver despesas nem encargos para esta instituição que seja decorrente da participação dessa pesquisa.

Os dados deste estudo foram coletados por meio de observação participante, em dois momentos, um inicial, para apuração do conhecimento previamente adquirido pelos alunos em suas relações sociais e o segundo momento, após a entrega da cartilha, apresentação do tema e descrição do processo de escovação bucal adequado, os dados coletados nos dois momentos foram comparados e os dados estão apresentados logo a seguir. 


\section{Resultados e Discussão}

$\mathrm{Na}$ escola, duas turmas dos anos iniciais do ensino fundamental foram selecionadas para a realização da coleta de dados, houve a participação de um quantitativo de quarenta e seis aluno, a observação inicial, permitiu a constatação de que cinquenta e seis por cento ( 26 alunos) deles, demonstraram o método de escovação de maneira insatisfatória, ao mesmo tempo, vinte e um por cento (10 alunos, dos que tentaram demonstrar a escovação, não sabiam realiza-la, e por fim, apenas vinte e um por cento (10 alunos), conseguiu realizar a higiene bucal, corretamente.

Gráfico 1- Resultado da observação inicial, apresentando em fatias os alunos que realizaram a escovação de maneira satisfatória, parcial e os que não sabiam realizar a escovação correta.

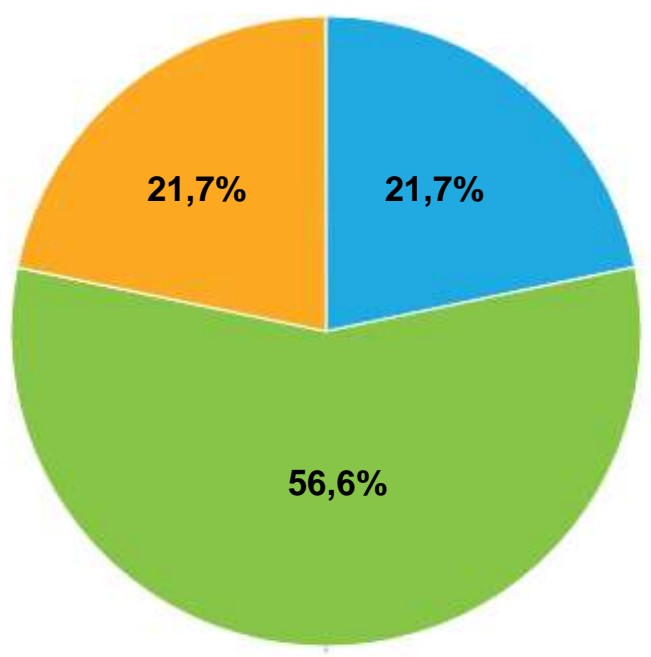

Realiza satisfatoriamente.

- Realiza parcialmente.

Não sabe realizar a escovação correta.

Fonte: Própria (2019)

Após a apresentação da cartilha e demonstração da pratica adequada de escovação, cada aluno, recebeu um kit com um creme dental, uma escova e fio dental, foi solicitado que cada aluno demonstrasse o método de escovação. Este segundo momento de observação, permitiu a constatação de que, depois do desenvolvimento da atividade, quatro por cento das crianças (2 alunos), realizaram o método de maneira insatisfatória, ao mesmo tempo, dezesseis por cento (8 alunos), dos que tentaram demonstrar a escovação, não sabiam realiza-la, por fim, oitenta por cento (36 alunos), conseguiram realizar a higiene bucal, corretamente. 
Gráfico 2- Resultado da segunda observação, apresentando em fatias os alunos que após a intervenção, realizaram a escovação de maneira satisfatória, parcial e os que não sabiam realizar a escovação correta.

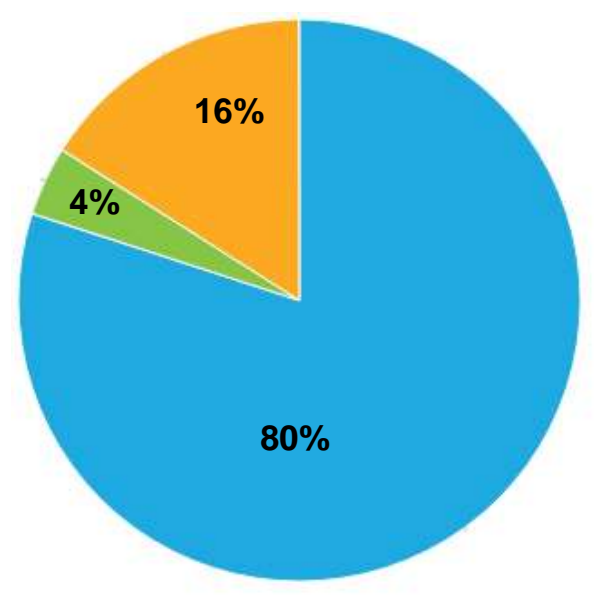

Realiza satisfatoriamente.

- Realiza parcialmente.

Não sabe realizar a escovação correta.

Fonte: Própria (2019)

Analisando os gráficos dos dois momentos acima descritos, é possível afirmar que, após o desenvolvimento das atividades didáticas, com uso da cartilha informativa, o número de alunos que realizou a escovação adequada subiu de $21,7 \%$ para $80 \%$, ou seja um progresso de $59,3 \%$ na realização da escovação.

De acordo com Barreto et al, (2013) A orientação em saúde bucal deve ser instituída já nos primeiros anos de vida, pois é nessa fase que a criança aprende e age de forma receptiva. $\mathrm{E}$ informações sobre saúde bucal nesta fase de desenvolvimento, são eficazes na redução do surgimento de problemas bucais como cárie e acúmulo de biofilme.

A faixa etária das crianças que foram observadas durantes as atividades desenvolvidas, estava entorno de seis e dez anos, autores como Gosuen (1997) e Guedes Pinto et al. (1981) comentam sobre os ensinamentos em relação à higiene bucal afirmando que a faixa etária de quatro a sete anos é a época mais oportuna para o estimulo do desenvolvimento de hábitos de higiene corretos. 


\section{Conclusões}

A promoção à saúde e a prevenção estão incluídas nas diretrizes da atenção básica e são ações que devem ser realizadas de maneira multiprofissional e interdisciplinar. A escola como espaço de educação favorece a constante aquisição de novos saberes e conhecimentos.

O uso da cartilha educativa "Higiene bucal: como fazer a escovação adequada", como recurso didático na promoção da saúde bucal, aplicada em duas escolas municipais de Vitoria de Santo Antão, pôde favorecer o processo de aprendizado dos alunos que participaram das atividades propostas, que por sinal demonstraram interesse e realizaram vários questionamentos para solucionar dúvidas.

O desenvolvimento e aplicação de recursos didáticos em sala de aula, que tragam uma abordagem multidisciplinar, contribuem no aprendizado e desenvolvimento de novas práticas promotoras de saúde, diminuindo assim, os índices de agravos à saúde bucal dos escolares.

\section{Referências}

ANTONIO, Luciana Pion et al. Avaliação de diferentes métodos educativos em saúde bucal em crianças na faixa etária de 7 a 10 anos de idade. RFO UPF, Passo Fundo, v. 20, n. 1, abr. 2015. Disponível em: < http://revodonto.bvsalud.org/pdf/rfo/v20n1/a10v20n1.pdf >. Acesso em 29 abr. 2019

AQUILANTE, A.G; ALMEIDA, B.S; CASTRO, R.F.M; XAVIER, C.R.G; PERES, S.H.C.S; BASTOS, J.R.M. A Importância da Educação em Saúde Bucal para Pré-Escolares. Revista de Odontologia da UNESP, São Paulo, v. 32, n. 1, p. 39-45, 2003. Disponível em: < http://s3.amazonaws.com/host-article-assets/rou/588017a17f8c9d0a098b4815/fulltext.pdf> Acesso em 29 abr. 2019

BARRETO, Débora Magalhães et al . Avaliação da eficácia de uma atividade educativo preventiva com pré-escolares: estudo piloto de um ensaio clínico randomizado. Arq. Odontol., Belo Horizonte , v. 49, n. 3, set. 2013 . Disponível em < http://revodonto.bvsalud.org/pdf/aodo/v49n3/a02v49n3.pdf >. Acesso em 29 abr. 2019

Brasil. Ministério da Saúde. Ministério da Saúde, Ministério da Educação. Caderno do gestor do Programa de Saúde Escolar. Brasília; 2015. Disponível em: < http://bvsms.saude.gov.br/bvs/publicacoes/caderno_gestor_pse.pdf> acesso em 27 abr. 2019.

BULGARELI, Jaqueline et al. A resolutividade em saúde bucal na atenção básica como instrumento para avaliação dos modelos de atenção. Ciênc. saúde coletiva, Rio de Janeiro, v. 19, n. 2, p. 383-391, Fev. 2014. . Disponível em < http://www.scielo.br/pdf/csc/v19n2/14138123-csc-19-02-00383.pdf >. Acesso em 28 abr. 2019.

CARVALHO, Theresa Hortênsia Leandro et al. Estratégias de promoção de saúde para crianças em idade pré-escolar do município de Patos-PB. Rev. odontol. UNESP, Araraquara, v. 42, n. 
6, p. 426-431, Dec. 2013 Disponível em < http://www.scielo.br/scielo.php?script=sci_arttext\&pid=S1807-25772013000600006>. Acesso 28 abr. 2019.

CÁRDENAS, S.D; MARTÍNEZ, K.R; VERGARA, K.M.A. Relação do nível de risco familiar total e cáries em estudantes da Boquilla, Cartagena. Avances en enfermeira, Bogotá, v. 31, n. 2, p. 43-52, July $2013 \quad$ Disponível em <http://www.scielo.org.co/scielo.php?script=sci_arttext\&pid=S0121 $45002013000200005 \& \operatorname{lng}=\mathrm{en} \& \mathrm{nrm}=\mathrm{iso}>$. Acesso em 02 Set. 2019

ENGEL, Guido Irineu. Pesquisa-ação. Educ. rev., Curitiba, n. 16, p. 181-191, dez. 2000. Disponível em <http://www.scielo.br/scielo.php?script=sci_arttext\&pid=S0104$40602000000200013 \& \operatorname{lng}=$ pt\&nrm=iso>. Acesso em 16 maio 2019.

GARBIN, Clea Adas Saliba et al. Prevalência de cárie dentária em pré-escolares de escolas de educação infantil de Araçatuba. São Paulo. Revista Odontológica de Araçatuba, v. 32, n. 2, p. 28-32, 2011. Disponível em: <http://hdl.handle.net/11449/133382>. Acesso 27 abr. 2019. prevalência de cárie em crianças. Rev. odontol. UNESP, Araraquara , v. 44, n. 5, p. 285291, Oct. $2015 . \quad$ Disponível em $<$ http://www.scielo.br/scielo.php?script=sci_arttext\&pid=S1807-

$25772015000500285 \& \operatorname{lng}=$ en\&nrm=iso>. Acesso em 02 Set. 2019.

GOSUEN, L. C. A importância do reforço constante na conscientização e motivação em higiene bucal. Rev. Paul. De Odontol., São Paulo, v. 19, n. 5, p. 30-32, 1997.

GRANVILLE-GARCIA, Ana Flávia et al. Importância da saúde bucal entre adolescentes de escolas públicas de Campina Grande/PB, Brasil. Rev. Pesq. Bras. Odontoped. Clin. Integr., João pessoa, jul/set. 2012. Disponível em: < http://bases.bireme.br/cgibin/wxislind.exe/iah/online/?IsisScript=iah/iah.xis \&src=google \&base=ADOLEC\&lang=p\&n extAction=lnk\&exprSearch=655295\&indexSearch=ID> acesso em 20 Set. 2019.

MARTEIS, L. S., MAKOWSKI, L. S., SANTOS, R. L. C. Abordagem sobre Dengue na educação básica em Sergipe: análise de cartilhas educativas. Scientia Plena, Aracajú, v. 7, n. 6, 2011. Disponível em:< https://www.scientiaplena.org.br/sp/article/view/191> . Acesso em: 12 abr. 2019.

MONTE, Diana. Oliveira. et al. Conscientização da Higienização bucal na população Brasileira. Ciências biológicas e da saúde. Recife, v. 2, n. 2. Dez 2015 p. 53-60. Disponível em: < https://periodicos.set.edu.br/index.php/facipesaude/article/download/3065/1676> acesso em 10 Ago, 2019.

OLIVEIRA, J. R. et al. Produção de cartilha "escorpião, que bicho é esse?": um recurso para o ensino na educação em saúde nas aulas de ciências. III Congresso Internacional das Lincenciaturas - COINTER, IFPE, 2016, 1-5 p. Disponível em: <https://institutoidv.org/wpcontent/uploads/2018/08/42-Jailson-Rodrigues-de-Oliveira.pdf> acesso em 27 Abr. 2019 
PAES, C. C. D. C., \& Paixão, A. N. dos P. (2016). A IMPORTÂNCIA DA ABORDAGEM DA EDUCAÇÃO EM SAÚDE. Revista De Educação Da Universidade Federal Do Vale Do São Francisco. $\quad$ v. 6 n. 11. 2016. Disponível em < http://www.periodicos.univasf.edu.br/index.php/revasf/article/view/38> acesso em 20 Abr 2019

PEREIRA, Gethesemane de Sousa et al. A PROMOÇÃO DA SAÚDE BUCAL NO CONTEXTO ESCOLAR: UMA REVISÃO INTEGRATIVA. Revista Expressão Católica Saúde, [S.1.], v. 2, n. 2, p. 09-16, aug. 2018. ISSN 2526-964X. Disponível em: $<$ http://publicacoesacademicas.unicatolicaquixada.edu.br/index.php/recsaude/article/view/211 1>. Acesso em: 28 Abr. 2019.

QUEIROZ, F.S; RODRIGUES, M.M.L.F; JUNIOR, G.A.C; OLIVEIRA, A.B; OLIVEIRA, J.D; ALMEIDA, E.R. Avaliação das condições de saúde bucal de Portadores de Necessidades Especiais. Rev Odontol UNESP, v. 43, n. 6, p. 396-401, nov./dez. 2014. Disponível em: < http://www.scielo.br/pdf/rounesp/v43n6/1807-2577-rounesp-43-06-0396.pdf>. Acesso em: 28 Abr. 2019.

ROCHA, A. R.; MELLO, W. N.; BURITY, C. H. F. A Utilização de modelos didáticos no ensino médio: uma abordagem em artrópodes. Saúde \& Ambiente em Revista, v. 5, n. 1, p. 2010.

Disponível em: http://publicacoes.unigranrio.edu.br/index.php/sare/article/view/1041 >. Acesso em: 28 Abr. 2019.

SILVA, P.F; FREITAS, C.H.S.M. Análise de motivos que dificultam a adoção de hábitos de higiene bucal saudáveis com relação à cárie dentária: avaliação de uma escola pública da Paraíba. Belo Horizonte. Arq Odontol, v. 47, n. 1, p. 38-44, jan./mar. 2011. Disponível em: < http://revodonto.bvsalud.org/pdf/aodo/v47n1/a06v47n1.pdf>. Acesso em: 28 Abr. 2019.

TEGAN, C; KOZLOWSKI, F.C; ROSÁRIO, M.L. Prevalência de cárie dentária em bebês e pré-escolares de Brotas, SP, Brasil. Odontologia e Sociedade, v. 9, n. 2, p. 24-30, 2007.

TURRIONI, Ana Paula Silveira et al . Avaliação das ações de educação na saúde bucal de adolescentes dentro da Estratégia de Saúde da Família. Ciênc. saúde coletiva, Rio de Janeiro , v. 17, n. 7, p. 1841-1848, Jul 2012 . Disponivel em $<$ http://www.scielo.br/scielo.php?script=sci_arttext\&pid=S1413-

$81232012000700023 \& \operatorname{lng}=$ en\&nrm=iso>. Acesso em 28 Set. 2019.

ZANELLA, Camila. As dificuldades que os professores enfrentam em sala de aula nos anos iniciais da docência. In: XI Congresso Nacional de Educação, Curitiba, PUCPR, setembro de 2013. Disponível em: < http://educere.bruc.com.br/arquivo/pdf2013/9875_6234.pdf > Acesso em 11 Ago, 2019. 